The author reported no conflicts of interest.

The Journal policy requires editors and reviewers to disclose conflicts of interest and to decline handling or reviewing manuscripts for which they may have a conflict of interest. The editors and reviewers of this article have no conflicts of interest.

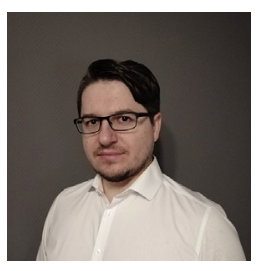

\section{WHAT DO WE KNOW ABOUT THE INDICATIONS FOR A}

\section{TRANSCAROTID APPROACH? \\ To the Editor:}

I read with great interest a recent article in which the authors compared the 30-day outcomes between patients who underwent transcarotid (TC) transcatheter aortic valve replacement (TAVR) with those who underwent transthoracic TAVR using the Sapien 3 valve (S3) (Edwards Lifesciences, Irvine, Calif).

Studies of various nontransfemoral approaches (eg, TC, transsubclavian, and transaxillar) are ongoing. Some of these approaches are extremely popular and indeed are among the most frequently used TAVR access routes. Globally, the transthoracic approach to TAVR is still among the procedures most supported by experience. Nontransfemoral approaches should be prioritized to increase the feasibility of transcatheter use while reducing the interventional risk in patients with peripheral artery disease or other conditions that reduce the suitability of femoral access.

However, Allen and colleagues ${ }^{1}$ did not mention the indications or contraindications for the TC approach and therefore failed to answer the following questions: How much interventional risk underlies this approach? and, Is the TC approach indicated in these patients?

Given the high rate of carotid stenosis $(48.5 \%)$, I do not believe that this patient selection for the TC approach is appropriate. Furthermore, the authors reported a stroke

\footnotetext{
The Editor welcomes submissions for possible publication in the Letters to the Editor section that consist of commentary on an article published in the Journal or other relevant issues. Authors should: $\bullet$ Include no more than 500 words of text, three authors, and five references. • Type with double-spacing. • See http://jtcs.ctsnetjournals.org/ misc/ifora.shtml for detailed submission instructions. • Submit the letter electronically via jtcvs.editorialmanager.com. Letters commenting on an article published in the JTCVS will be considered if they are received within 6 weeks of the time the article was published. Authors of the article being commented on will be given an opportunity of offer a timely response ( 2 weeks) to the letter. Authors of letters will be notified that the letter has been received. Unpublished letters cannot be returned.
}

rate of $4.3 \%$ in the TC group, slightly higher than that in the transthoracic group. ${ }^{1}$ In the Sapien Aortic Bioprosthesis European Outcome Registry, ${ }^{2}$ where $93 \%$ of nontransfemoral approaches were transthoracic using the S3, the stroke rate was $2.8 \%$ and the 30 -day mortality was $4 \%$. Furthermore, when an aortic no-touch technique is necessary, transthoracic-TAVR was shown to yield even better outcomes than transfemoral-TAVR. ${ }^{3}$

Although Allen and colleagues ${ }^{1}$ reported a low vascular injury rate, the risk remains high, and patients with carotid stenosis are unsuitable for TC-TAVR, independent of whether or not it is carried out via a percutaneous or cutdown procedure. Furthermore, a minimum carotid vessel diameter is required for the TC approach, and stenosisfree vessels are of paramount importance. ${ }^{4}$ Further, vascular complications affecting the carotid arteries would have more significant negative effects than similar injuries affecting femoral or subclavian arteries. This would become almost unacceptable in younger and lower risk patients.

Remarkably, paravalvular leakage (PVL) outcomes were not reported by the authors. ${ }^{1}$ The topic of mild PVL is the most prevalent issue affecting the use of the S3. In contrast, Folliguet and colleagues ${ }^{4}$ reported moderate to severe PVL in $18.6 \%$ of patients after TC-TAVR with self-expandable and balloon-expandable valves. Because Allen and colleagues $^{1}$ reported only 30 -day outcomes, the presence and severity of PVL would represent not only a surrogate 30-day marker but also a window to the eventual prediction of long-term outcomes.

Finally, similar to the transfemoral TAVR, not every patient might be suitable for only 1 nontransfemoral approach. The availability of various TAVR approaches provides surgeons with a rich opportunity to select the best option for the given scenario. I therefore believe that the differentiation of the various clinical indications for the appropriate TAVR approach is necessary.

Dritan Useini, $M D$ Department of Cardiothoracic Surgery Ruhr-University Hospital Bergmannsheil Bochum, Germany

\section{References}

1. Allen KB, Chhatriwalla AK, Saxon J, Hermiller J, Heimansohn D, Moainie S, et al. Transcarotid versus transthoracic access for transcatheter aortic valve replacement: a propensity-matched analysis. J Thorac Cardiovasc Surg. October 21, 2020 [Epub ahead of print].

2. Wendler O, Schymik G, Treede H, Baumgartner H, Dumonteil N, Ihlberg L, et al SOURCE 3 registry: design and 30-day results of the European postapproval registry of the latest generation of the SAPIEN 3 transcatheter heart valve. Circulation. 2017;135:1123-32.

3. Useini D, Haldenwang P, Schlömicher M, Christ H, Naraghi H, Moustafine V, et al Mid-term outcomes after transapical and transfemoral transcatheter aortic valve implantation for aortic stenosis and porcelain aorta with a systematic review of transfemoral versus transapical approach. Thorac Cardiovasc Surg. 2020;68: $623-32$. 